\title{
Serial discrimination reversal learning as a repeated-acquisition method to test drug effects
}

\author{
WILLIAM H. CALHOUN and ELIZABETH A. JONES \\ University of Tennessee, Knoxville, Tennessee 37916
}

\begin{abstract}
A repeated-acquisition procedure utilizing serial discrimination reversal (SDR) was developed to test drug effects on acquisition. Rats were trained on SDR until successive acquisitions were uniform and repeatable. Scopolamine, DL-amphetamine, and tranylcypromine were tested for effects on acquisition with this method. DL-amphetamine and tranylcypromine facilitated acquisition; scopolamine disrupted discrimination.
\end{abstract}

This paper reports results of a repeated-acquisition procedure developed for use with rats. Repeatedacquisition procedures derive from work by Boren (e.g., Boren \& Devine, 1968) and have been extended by Calhoun and Jones (1974a, 1974b) and Thompson (1970, 1971). In the Boren procedure, monkeys were trained to respond in a four-unit chain. The manipulanda were four groups of three response levers, and the monkeys were required to press a given sequence of four levers, one from each group, in order to receive food. Errors during the acquisition of each successive response chain were recorded. Following training of many sequences of four-unit chains, acquisition of new chains was uniform and stable. Thus, Boren and Devine had established a baseline of acquisition. Thompson $(1970,1971)$ modified this procedure for use with pigeons. The subjects were trained to peck at one of four response keys with a specific sequence of keys, each identified by a different hue, defined as correct. After the animals had learned many such sequences, acquisition of additional sequences followed a predictable pattern. Thompson $(1973,1975)$ next tested for drug effects on this baseline. In this paper, we demonstrate that a similar procedure can be used with rats, and that a repeatable baseline of acquisition can be obtained. Next, the effects of several drugs were tested.

\section{DEVELOPMENT OF A REPEATED-ACQUISITION BASELINE}

One type of repeated-acquisition procedure is serial discrimination reversal (SDR) learning (Khavari \& Heise, 1967; Kulig \& Calhoun, 1972). In SDR, an animal first learns to discriminate between two stimuli with one being positive (S+) and one negative (S-). After learning this discrimination, the $\mathrm{S}+$ and $\mathrm{S}-$ are

The basic data of this paper were presented at the annual meeting of the Society of Experimental Biology, Atlantic City, 1974. switched, and the animal learns the reversal discrimination. This procedure is continued through a series of such reversals, hence the label of SDR learning. There are two kinds of learning that take place in this situation: (1) learning to learn serial discrimination, and (2) the learning of each successive discrimination. In this paper, we will focus on the learning of each successive discrimination. Thus, the specific operational definition of learning used was acquisition of a specific discrimination based upon the reversal of a discrimination learned in the previous session.

\section{Method}

Subjects. Male Wistar rats, obtained from a commercial supplier when they weighed $200-250 \mathrm{~g}$, served as subjects. The rats were maintained with ad-lib food and water in the University of Tennessee's animal facility until the experiment began. They were then placed on a 23-h water-deprivation schedule and moved to the laboratory. Food continued ad lib.

Apparatus. The apparatus consisted of standard operant chambers with a single lever. A white cue light was mounted in the operant chamber $6 \mathrm{~cm}$ above the lever and served as one of two stimuli. A Sonalert signal device $(4,900 \mathrm{~Hz})$ was mounted outside the chamber and served as the tone stimulus. Reinforcement consisted of a $.1 \mathrm{ml}$ of $9 \%$ sucrose solution delivered by a drinking spout mounted $6 \mathrm{~cm}$ to the left of the response lever. The operant chambers were illuminated by a $7-\mathrm{W}$ red houselight during the sessions. The chambers were enclosed in sound-deadened cubicles that were ventilated by a small fan. The apparatus was controlled by standard relay circuitry mounted on racks outside the experimental chamber. A printout counter recorded cumulative error scores in 10-trial blocks.

Procedure. After the animals were adjusted to the waterdeprivation schedule and habituated to the apparatus, they were hand shaped to barpress for a drop of sucrose. When shaping was completed, the animals were given daily sessions of continuous reinforcement until barpressing rate was consistently high. Next, the animals were introduced to the discrete-trial operant procedure in which either a tone or a light occurred during a 6-sec trial. A response during either tone or light trial terminated the trial and delivered a drop of sucrose in the drinking spout. Trials were separated by a 10 -sec intertrial interval (ITI). Trial order was semirandomized in a 20-unit Gellerman sequence. Intertrial responses were suppressed by means of an ITI reset; any response during the interval reset the timer, causing the prolongation of the ITI. During the 
early part of the discrete-trial training, the ITI reset was disconnected to facilitate acquisition of the discrete-trial behavior.

After six sessions of 200 discrete trials, 100 tone and 100 light trials per daily session, the animals were started on discrimination reversals. During this phase of training, each animal was randomly assigned tone or light as $\mathrm{S}+$ for the first discrimination. The animals were trained on each discrimination for one 200-trial session. In discrimination sessions, a single response during the $\mathrm{S}+$ trial caused termination of the trial and delivered a drop of sucrose. These barpresses were reported as $\mathrm{S}+$ responses. The first response during the $\mathrm{S}-$ trial did not terminate the trial, but was counted as an $S-$ response and designated as an error. ITI responses also were recorded.

\section{Results}

The animals were trained through a series of reversals until acquisition during each successive discrimination occurred rapidly (approximately 25 reversals). Cumulative error data for three rats appear in Figure 1. Data were taken for four successive sessions after behavior was stable.

As can be seen from the figure, most errors occurred early in the session, and errors decreased in frequency as a function of trials. Thus, the behavior within each session follows the "typical" learning curve. Rat 16-1's behavior was not as uniform as that of Rats 15-1 and $17-1$, as acquisition was rather slow, with errors occurring throughout the session. Rat 17-1 showed very uniform data. At this point, it is necessary to note that the total number of errors during the 200-trial acquisition session provides a single measure of acquisition. This measure will be used in later sections.

\section{Discussion}

The "learning" curves obtained in baseline SDR follow the pattern of the "general" learning curve; more errors occur early in the session and decrease in frequency directly as a function of trials. There is, of course, some question whether such repeated acquisitions are mediated by the same underlying
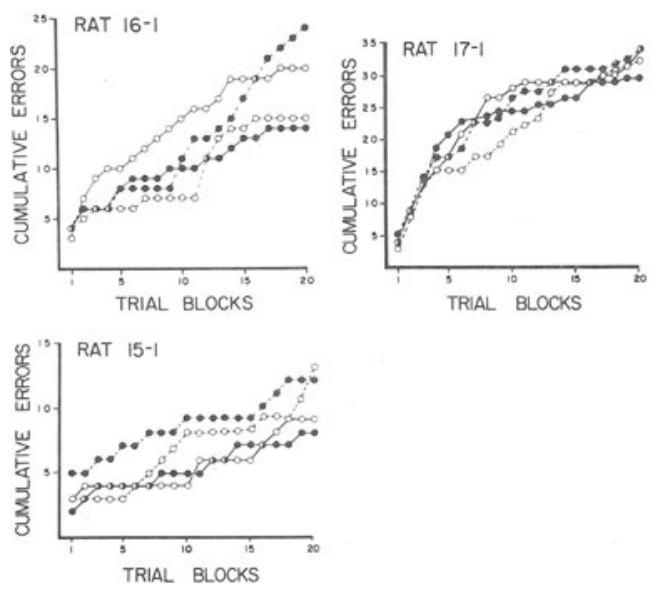

Figure 1. Cumulative errors for acquisition for four consecutive serial discrimination reversals for Rats 15-1, 16-1, and 17-1. process as initial acquisition. The basic problem is the same for the initial and repeated acquisition; namely, learning which cue is correct and which is incorrect. Also, the shape of the repeated learning curve shows that the repeated-acquisition process is similar to the initial acquisition process. Thus, it seems reasonable to conclude that the SDR procedure does produce a repeated-acquisition baseline for positively reinforced operant discrimination learning.

\section{DRUG EFFECTS ON THE REPEATED-ACQUISITION BASELINE}

Adrenergic drugs have been shown to improve performance in a variety of tasks, and there is evidence that they also accelerate learning (e.g., Grossman \& Sclafani, 1971). Earlier work in our laboratory suggests that adrenergic drugs reduce the number of errors in SDR (Handley, 1972; Kulig \& Calhoun, 1972). Thus, DL-amphetamine and tranylcypromine were selected for study. Scopolamine, an anticholinergic drug, was tested, as there has been considerable speculation that this drug interferes with learning and memory (e.g., Carlton \& Markiewicz, 1971). Doses of drugs were selected from pilot research. These doses were shown to be behaviorally active, but not high in comparison to the ED 50.

\section{Method}

Subjects. Two groups of subjects were used; the subjects were male Wistar rats, obtained from a commercial supplier when they weighed $200-250 \mathrm{~g}$. The rats were trained on SDR until performance during successive reversals was stable, approximately $\pm 50 \%$ of their base error rates. The rats were housed three per cage and maintained on ad-lib food. During experimental testing, they were maintained on a $23-\mathrm{h}$ waterdeprivation schedule.

Apparatus. The apparatus was the same as described earlier.

Procedure. The animals were tested daily in sessions of $100 \mathrm{~S}+$ and $100 \mathrm{~S}-$ trials. Trials were $6 \mathrm{sec}$, with an ITI of $10 \mathrm{sec}$. One group of rats was tested following injection of one of the three drugs or saline. A 4 by 4 Latin square was used to counterbalance the order of drugging. A second group of five rats was tested with three doses of tranylcypromine to develop a dose response curve for this drug. In this case, the order of dosing was randomized. The rats were drugged only once per week with intervening sessions to permit complete elimination of the drug and to reestablish the baseline.

\section{Results}

The data appear in Tables 1 and 2. Examination of Table 1 shows that the adrenergic drugs improved performance over the saline condition. The animals responded on nearly all $\mathrm{S}+$ trials, but all subjects made fewer errors than when injected with saline. The reduction in errors was $46 \%$ for DL-amphetamine and $78 \%$ for tranylcypromine. (Note: One rat did not respond at all after receiving the injection of DL-amphetamine.) Intertrial responses did not vary systematically with drug type, and some subjects had more ITIs when drugged (two of three for DL-amphetamine; one of four for tranylcypromine). Scopolamine $(.5 \mathrm{mg} / \mathrm{kg})$ severely disrupted the 
Table 1

Mean and Range of Drug Effects on Baseline SDR for Four Rats

\begin{tabular}{llrr}
\hline \multicolumn{1}{c}{ Condition } & Measure & Mean & Range \\
\hline \multirow{4}{*}{ Saline } & S+ & 98.5 & 4 \\
& S- & 19.0 & 20 \\
DL-amphetamine & ITI & 16.8 & 18 \\
& S+ & 100.0 & 0 \\
& S- & 10.3 & 4 \\
Tranylcypromine & ITI & 23.7 & 8 \\
& S+ & 98.2 & 4 \\
Scopolamine & S- & 4.2 & 3 \\
& ITI & 12.0 & 13 \\
& S+ & 24.0 & 51 \\
& S- & 14.0 & 13 \\
& ITI & 20.8 & 23 \\
\hline
\end{tabular}

Note-One rat failed to respond at all under DL-amphetamine; its data were not included.

Table 2

Tranylcypromine's Effect in Baseline SDR

\begin{tabular}{|c|c|c|c|c|c|c|c|}
\hline \multirow{3}{*}{$\begin{array}{l}\text { Dose } \\
(\mathrm{mg} / \mathrm{kg})\end{array}$} & \multicolumn{2}{|c|}{ S+ Responses } & \multicolumn{5}{|c|}{ Errors } \\
\hline & \multirow[b]{2}{*}{ Median } & \multirow{2}{*}{$\begin{array}{l} \pm 1 / 2 \\
\text { Range }\end{array}$} & \multicolumn{5}{|c|}{ Subject } \\
\hline & & & 1 & 2 & 3 & 4 & 5 \\
\hline Saline & 96 & 2.5 & 24 & 35 & 17 & 36 & 40 \\
\hline .5 & 98 & 1.0 & 18 & 12 & 22 & 11 & 27 \\
\hline 1.0 & 94 & 4.0 & 13 & 15 & 15 & 24 & 20 \\
\hline 2.0 & 61 & 48.5 & 5 & 9 & 9 & 16 & 15 \\
\hline
\end{tabular}

discrimination behavior; the subjects responded to few S+ trials, yet made nearly as many errors as with saline. No clear conclusion can be reached regarding the drug's effect on learning without a dose-response and trial-by-trial analysis.

In Table 2, the results of a dose-response study for tranylcypromine are shown. Statistical tests of each drug condition against the saline condition were conducted using a Wilcoxon signed-rank test. For $.5 \mathrm{mg} / \mathrm{kg}$, the difference was marginally significant $(p=.062)$, and significant for $1.0 \mathrm{mg} / \mathrm{kg}(\mathrm{p}=.031)$. The results for $2.0 \mathrm{mg} / \mathrm{kg}$ were not useful, as the animals missed too many $\mathrm{S}+$ trials.

\section{Discussion}

This experiment established that drugs effect acquisition studied with baseline SDR in different ways. DL-amphetamine and tranylcypromine enhanced acquisition in low doses; $\mathrm{S}+$ responding was high, while errors were greatly reduced. High drug doses disrupt behavior. These results are quite in keeping with numerous reports that stimulant drugs improve learning assessed in a variety of traditional ways. The efficacy of the SDR method should be stressed; a small number of animals can be used and effects can be studied through a within-subjects design. Another advantage of the SDR method is the use of positive reinforcement. In many studies of drug effects on learning, shock escape/avoidance procedures are used where the drug effect on the motivational properties of shock are totally confounded with effects on association.

\section{SUMMARY AND CONCLUSION}

The SDR procedure can be used to develop an animal model for testing drug effects of acquisition of operant behavior controlled by position reinforcement. Low doses of drugs appear most effective, as high doses tend to disrupt normal responding. Generally, stimulant drugs of the adrenergic type enhance responding and accelerate the rate of acquisition.

One limitation of the SDR method is that any drug that reduces $S+$ responding cannot readily be evaluated. The most compelling demonstration of a drug effect is when one dependent variable (e.g., St response frequency) remains unchanged while the other, error frequency, either decreases or increases. A drug that reduces both $\mathrm{S}+$ and $\mathrm{S}-$ responding cannot be evaluated for a specific effect on learning.

\section{REFERENCES}

Boren, J. J., \& Devine, D. D. The repeated acquisition of behavioral chains. Journal of the Experimental Analysis of Behavior, 1968, 11, 651-660.

Calhoun, W. H., \& Jones, E. A. Methamphetamine's effect on repeated acquisition with serial discrimination reversals. Psychopharmacologia, 1974, 39, 303-308. (a)

Calhoun, W. H., \& Jones, E. A. Repeated acquisition for studying drug effects on acquisition. Federation Proceedings, 1974, 33, 550. (Abstract) (b)

Carlton, P. L., \& Markiewicz, B. Behavioral effects of atropine and scopolamine. In E. Furchtgott (Ed.), Pharmacological and biophysical agents and behavior. New York: Academic Press, 1971.

Grossman, S. P., \& Sclafani, A. Sympathomimetic amines. In E. Furchtgott (Ed.), Pharmacological and biophysical agents and behavior. New York: Academic Press, 1971.

HANDLEY, G. W. The effects of methylphenidate (Ritalin) upon performance in the successive discrimnation reversal situation. Unpublished doctoral dissertation, University of Tennessee, Knoxville, 1972.

KhaVARI, K. H., \& Heise, G. A. Analysis of discrimination reversal in the rat. Psychonomic Science, 1967, 9, 271-272.

Kulig, B. M., \& CalHoun, W. H. Enhancement of successive discrimination reversal learning by methamphetamine. Psychopharmacologia, 1972, 27, 233-240.

Thompson, D. M. Repeated acquisitions as a behavioral baseline. Psychonomic Science, 1970, 21, 156-157.

Thompson, D. M. Transition to a steady state of repeated acquisition. Psychonomic Science, 1971, 24, 236-238.

Thompson, D. M. Repeated acquisition as a behavioral baseline for studying drug effects. Journal of Pharmacology and Experimental Therapists, 1973, 184, 506-514.

Thompson, D. M. Repeated acquisition of response sequence: Stimulus control and drugs. Journal of the Experimental Analysis of Behavior, 1975, 23, 429-436.

(Received for publication February 23, 1979.) 